\title{
Los conflictos jurisdiccionales entre la justicia real y el Santo Oficio en la Castilla del siglo XVII: las Juntas de Competencias y la circulación de alegaciones jurídicas*
}

\author{
Jurisdictional Conflicts within the Royal Justice and the \\ Holy Inquisition in the / $7^{\text {th }}$ - century Castile: \\ The Juntas de Competencias and the Circulation of Legal Claims
}

\section{INÉS GÓMEZ GONZÁLEZ}

\author{
Universidad de Granada \\ Facultad de Filosofía y Letras \\ Departamento de Historia Moderna y de América \\ Campus Universitario de Cartuja \\ |807| Granada (España) \\ igomezg@ugr.es
}

(iD)

RECIBIDO: FEBRERO DE 202

ACEPTADO: MARZO DE 202

Resumen: En Castilla, como en otros territorios de la monarquía, los conflictos de competencias entre la justicia real y el Santo Oficio fueron constantes a lo largo del Antiguo Régimen, a pesar de que en I553 se había firmado una concordia en la que se delimitaba el ámbito de actuación de ambas jurisdicciones. Estos enfrentamientos tuvieron un amplio eco en la sociedad y propiciaron la circulación de numerosísimas alegaciones jurídicas, cuyo análisis nos permitirá arrojar alguna luz sobre las Juntas de Competencias creadas para solucionar estas desavenencias.

Palabras clave: Junta de competencias. Conflictos jurisdiccionales. Inquisición. Castilla. Siglo XVII. Alegaciones jurídicas. Informaciones en Derecho. Porcones

Abstract: As in other territories of the monarchy, in Castile, conflicts of jurisdiction between the Royal Justice and the Holy Inquisition were consistent throughout the Old Regime, despite the signing in 1553 of an agreement to limit the scope of action of both jurisdictions. These confrontations had a wide echo in society and led to the circulation of multiple legal claims, which analysis will allow us to shed some light on the Competency Boards created to solve these disputes.

Keywords: Junta de competencias. Jurisdictional conflicts. Inquisition. Castile. I $7^{\text {th }}$ century. Legal claims. Porcones

\footnotetext{
* Este trabajo se inscribe en el marco del proyecto de investigación $1+D$ Los usos sociales de las defensas jurídicas: publicación y circulación de los porcones en el Antiguo Régimen (HAR2017-82817-P), financiado por el Ministerio de Economía y Competitividad.
}

MEMORIA Y CIVILIZACIÓN 24 (202I): 87-I04 [I-18] [ISSN: II39-0I07; ISSN-e: 2254-6367]

87

DOI: https://doi.org//0.1558I/00I.24.008 
INÉS GÓMEZ GONZÁLEZ

\section{INTRODUCCIÓN}

Como es de sobra conocido, los conflictos jurisdiccionales fueron una constante a lo largo de todo el Antiguo Régimen. Estos conflictos acarrearon un sinfín de problemas, entre otros, la excesiva dilación en la resolución de los negocios, y pusieron en entredicho el funcionamiento del sistema polisinodial. Para dirimir estas disputas, en las que se vieron involucradas todas las instituciones de la Corona - tanto las de carácter central, que residían en la corte, como las que ejercían sus funciones a lo largo del vasto territorio de la monarquía-, se arbitraron distintas medidas. Entre ellas caben destacarse la firma de concordias y, sobre todo, la creación de juntas particulares de carácter temporal, las llamadas Juntas de Competencias. Se trataba de un mecanismo que hundía sus raíces en el reinado de los Reyes Católicos, consistente en la reunión de individuos de los organismos en conflicto, al que se recurrió a lo largo de los siglos XVI y XVII'. En 1625, debido a la magnitud que había alcanzado el problema, Felipe IV instituyó una junta permanente, a la que se conoce como Junta General o Junta Grande de Competencias ${ }^{2}$.

Esta Junta, cuya creación debe relacionarse asimismo con los intentos del conde-duque de Olivares de controlar el aparato administrativo y de relegar a un segundo plano el poder de los Consejos, funcionó durante dos periodos: el primero se extendió de 1625 a 1643; y el segundo de 1656 a I665. A la hora de analizar el significado de esta Junta, la historiografía ha hecho hincapié en la oposición del Consejo de Castilla a su establecimiento y ha relacionado su extinción con un fortalecimiento del gobierno tradicional de la monarquía a través de los Consejos ${ }^{3}$. Ahora bien, hay que tener en cuenta igualmente que la eficacia de la Junta Grande de Competencias fue limitada, entre otras razones, porque su convocatoria alargaba la determinación de los procesos ${ }^{4}$. En cualquier caso, lo que interesa señalar es que tras su desaparición se volvió a la antigua forma de resolver los conflictos de competencias a través de la convocatoria de juntas particulares de carácter temporal; unas juntas a las que, por otra parte, se había seguido recurriendo durante su existencia ${ }^{5}$.

\footnotetext{
I Sánchez González, 1993, p. 40 y Baltar Rodríguez, 1998, pp. 727 y ss.

2 Sobre esta Junta Sánchez González, 1995, pp. 133 y ss.; Baltar Rodríguez, 1998, pp. 747 y ss.; García-Badell Arias, 2004; y Barrios, 2005, pp. 396-4I0.

${ }^{3}$ García-Badell Arias, 2004; Ezquerra Revilla, 2017, pp. 820-823; y Martínez Millán, 2017b, pp. 322 y ss.

${ }^{4}$ Baltar Rodríguez, 1998, pp. 757-758.

${ }^{5}$ Baltar Rodríguez, 1998, p. 753.
} 
Por lo que se refiere a los conflictos con la Inquisición, basta echar un vistazo a las obras clásicas de Llorente y Lea para apreciar las dimensiones que alcanzaron las competencias jurisdiccionales entre el Santo Oficio y los tribunales civiles y eclesiásticos en los tiempos modernos ${ }^{6}$. Unas competencias que, es necesario subrayar, fueron especialmente complejas, dada la doble naturaleza jurisdiccional -temporal y eclesiástica- del Santo Oficio ${ }^{7}$. La mayoría de los problemas con los tribunales reales, los que aquí nos conciernen, surgieron por cuestiones de índole protocolaria y, sobre todo, por los amplios privilegios concedidos a los oficiales y familiares de la Inquisición, a pesar de que en teoría se habían delimitado los campos de actuación de ambas jurisdicciones.

En Castilla, el territorio en el que fijaremos nuestra atención en las páginas que siguen, se firmó una concordia en 1553 con el fin de solucionar estos conflictos «amistosamente» ${ }^{8}$. Dicha concordia ${ }^{9}$ reconocía de forma implícita el fuero privilegiado de los oficiales de la Inquisición, pero limitaba el de los familiares ${ }^{10}$. De hecho, las causas civiles y buen número de causas criminales en las que se vieran involucrados los familiares quedaban reservadas a la jurisdicción real. Así, la justicia ordinaria tenía competencia sobre todos los procesos civiles de los familiares, ya fueran demandantes o demandados. Por lo que respecta a los pleitos criminales, correspondía a la jurisdicción real resolver determinados delitos - como los de lesa majestad, pecado nefando, violación o rapto de mujeres-y se dejaba al Santo Oficio el conocimiento de las causas penales no tipificadas, sin precisar cuáles eran esas causas". Un hecho que, como veremos, generó mucha controversia a la hora de determinar qué delitos estaban exceptuados.

Para dirimir los conflictos jurisdiccionales que pudieran surgir, la concordia establecía un mecanismo denominado competencia. Este consistía en el envío del asunto sobre el que se disputaban el conocimiento las dos jurisdicciones a una Junta de Competencias formada por cuatro miembros - dos de la Suprema y dos del Consejo de Castilla - y si esta junta no llegaba a un acuerdo, el monarca

${ }^{6}$ Ver especialmente Llorente, 1818 y 1836 , V, pp. 12 y ss.; y Lea, I983, I, PP. 48I-589.

7 En palabras de Tomás y Valiente, «el carácter mixto de la jurisdicción inquisitorial constituyó para el Santo Oficio un arma táctica que utilizó eficazmente para aumentar y defender su independencia, apoyándose para ello bien en la autoridad pontificia, para evitar una excesiva sujeción al poder real, o bien en la autoridad de la Corona cuando le interesó garantizar su distanciamiento respecto a la Curia romana», Tomás y Valiente, 1982, p. 18. Acerca de este tema consúltense, asimismo, Gacto Fernández, 2012; y Maqueda Abreu, 1997.

8 Domínguez Ortiz, 2010, p. 79.

${ }^{9}$ Recogida en la Recopilación de las leyes destos reinos (o Nueva Recopilación), IV, I, I 8 y en la Novísima Recopilación, II, 7, I.

10 Lea, 1983, ı, p. 489.

II Lea, 1983, I, pp. 489-490; y Contreras, 1982, pp. 73-74. Sobre la cuestión del fuero inquisitorial resultan imprescindibles las reflexiones de López Vela, 1993, pp. 192 y ss. 
solventaba la diferencia en última instancia ${ }^{2}$. La historiografía ha puesto de manifiesto que, de forma general, los reyes fallaron a favor del Santo Oficio desde la segunda mitad del Quinientos hasta mediados del Seiscientos, cuando empezaron a dar resoluciones contrarias a la Inquisición ${ }^{13}$. Dejando a un lado esta cuestión y volviendo al mecanismo de la competencia, es preciso indicar que estuvo en vigor durante los siglos XVI y XVII, aunque a lo largo del tiempo sufrió algunas modificaciones, pues tras la creación de la Junta Grande de Competencias en I625, y durante los dos periodos que estuvo en funcionamiento, era esta junta la que resolvía en última instancia en lugar del monarca ${ }^{14}$.

No obstante, la concordia no impidió que los choques entre la jurisdicción real y la inquisitorial fueran constantes en la época de los Austrias ${ }^{15}$. Tanto es así que en 1696, como es bien sabido, Carlos II convocó una junta, la llamada Junta Magna, con el fin de limitar la jurisdicción de la Inquisición ${ }^{16}$. Los enfrentamientos entre ambas instancias tuvieron un amplio eco en la sociedad y propiciaron la circulación de numerosísimas alegaciones jurídicas, cuyo análisis nos permitirá arrojar alguna luz sobre el funcionamiento y la eficacia de las Juntas de Competencias creadas para solucionar estos conflictos.

\section{LAS ALEGACIONES JURÍDICAS Y LAS JUNTAS DE COMPETENCIAS}

En Castilla, como en el resto de territorios de la monarquía y en otros países europeos, fue muy habitual que durante el desarrollo de los procesos judiciales las partes mandasen publicar alegaciones jurídicas, en las que se narraban los hechos que habían originado el pleito y se exponían asimismo los argumentos jurídicos de la defensa. La función esencial de estas alegaciones jurídicas, a las que también se denomina informaciones en derecho y porcones, era crear una corriente de opinión favorable a los intereses de los litigantes que habían promovido su redacción e incidir igualmente en el ánimo de los jueces que debían sentenciar la causa. La publicación de estas alegaciones, que no estaba sujeta a ninguna censura previa, y su posterior circulación dio lugar a un debate público muy interesante, no solo por la repercusión que una determinada alegación pudiera tener en un momento concreto, sino porque con frecuencia todos los actores

\footnotetext{
12 Lea, 1983, ı, p. 490.

13 Martínez Millán, 1985, p. 218 . Domínguez Ortiz matiza esta afirmación, ya que, en su opinión, Felipe II dejó de favorecer a la Inquisición al final de su reinado, Domínguez Ortiz, 2000, pp. 64-65.

14 Martínez Millán, 1985, pp. 224-225.

15 Melo Flórez, 2016.

16 Las propuestas de esta junta no llegaron a materializarse, aunque fueron retomadas por Macanaz cuando se propuso reformar el Santo Oficio en I7/4. Acerca de este asunto, Egido, 1984; Martínez Millán, 1985 y $2017 a$; Vallejo García-Hevía, 1996; y López Vela, 2014.
} 
en conflicto dieron a la luz alegaciones en las que rebatían los argumentos de la parte contraria ${ }^{17}$. Los fiscales de los tribunales de la monarquía no fueron ajenos a esta práctica de redactar alegaciones en defensa de su jurisdicción, especialmente cuando estallaba un conflicto de competencias.

En el caso que nos ocupa, las competencias entre la jurisdicción real y la inquisitorial en Castilla, hemos constatado que los particulares y los fiscales de los tribunales reales e inquisitoriales publicaron un sinfín de alegaciones. La mayoría se referían a asuntos concernientes a los familiares de la Inquisición, ya fueran controversias suscitadas en torno al reconocimiento del fuero de alguno de ellos ${ }^{18}$ o diferencias surgidas a la hora de establecer qué delitos estaban exceptuados en la concordia. A veces, los autores de estas informaciones en derecho se dirigían directamente a los miembros de la junta encargada de dirimir la competencia, con el fin de convencerles de que resolvieran a favor del tribunal al que estaban representando. Así lo hace, por citar solo un ejemplo, un fiscal de la Inquisición de Murcia, don Juan Adam de la Parra.

El 28 de mayo de 1634 Adam de la Parra dio a la luz una alegación, en la que pedía a los «señores» de la Junta de Competencias que remitiesen al Santo Oficio el proceso iniciado tras la muerte de don Pedro Celdrán ${ }^{19}$. Celdrán había sido asesinado durante un partido de juego de pelota en el Arenal de Murcia, resultando culpados dos hermanos, don Diego y don Jorge Bernal. La Inquisición murciana reclamó la causa, al ser ambos familiares del Santo Oficio. Sin embargo, el juez de comisión enviado para averiguar lo acontecido, el licenciado Antonio Amigo de Arenillas, formó competencia, ya que pensaba que los acusados no podían gozar del fuero inquisitorial. En primer lugar, porque se habían fugado y no habían solicitado el privilegio de disfrutar del fuero como era preceptivo; y, en segundo lugar, porque don Diego Bernal no tenía las calidades suficientes para ser considerado familiar, pues unos meses antes había sido condenado a seis años de destierro tras cometer otro asesinato. A lo largo de la alegación, Adam de la

17 Sobre la cuestión Coronas González, 2003; y Gómez González, 2016 b y 2017.

18 Así, en 164I, por señalar un caso, el fiscal de la Chancillería de Granada publicó una alegación negando el fuero inquisitorial a don Francisco de Arenzana, un vecino de Guadix que decía ser familiar del Santo Oficio, y a su mujer, doña María de Espinosa, tras ser acusados de raptar a su hija. Según el fiscal del tribunal granadino, el asunto debía verlo la Chancillería, porque, entre otras razones, no se había probado que Arenzana fuera familiar del número, El licenciado don Juan Pérez de Lara, fiscal de su majestad en esta Real Audiencia y Chancillería por su Real jurisdicción. En el pleito de competencia sobre la exempción de fuero que pretende Francisco de Arenzana, y doña María de Espinosa su mujer por familiar del Santo Oficio de la Inquisición, Granada, Imprenta Baltasar de Bolívar, 164I, Biblioteca Nacional de España [BNE], Porcones, 954-34 (caja 2).

19 Por el licenciado don Juan de Adam de la Parra, fiscal de la Inquisición de Murcia, contra la justicia Real de dicha ciudad, y el licenciado Antonio Amigo de Arenillas, juez pesquisidor para la averiguación y castigo de los culpables en la muerte de don Pedro Celdrán. Sobre qué se debe de remitir por los señores del Consejo de su majestad, de la Junta de Competencias, el conocimiento de esta causa a el Santo Oficio, en cuanto toca a don Diego y a don Jorge Bernal, hermanos, familiares del Santo Oficio de la ciudad de Murcia, BNE, Porcones, 954-38 (caja 2). 
Parra refutaba todos los argumentos del comisionado regio y desarrollaba los artículos en los que, en su opinión, se fundaba la jurisdicción inquisitorial.

En esta información en derecho el fiscal de la Inquisición de Murcia se limitaba, por tanto, a defender su jurisdicción. Pero en otros casos las alegaciones iban más allá y mostraban los problemas a la hora de resolver los conflictos a través de la convocatoria de Juntas de Competencias. No en vano, muchas ponían de manifiesto el incumplimiento de los capítulos de la concordia de 1553 por parte de la justicia real y el Santo Oficio. Tal cosa sucedía si una de las dos jurisdicciones se negaba a declarar o a aceptar los términos de la llamada competencia, que, recordémoslo, era el mecanismo previsto para dirimir los conflictos, que daba lugar, precisamente, a la constitución de una Junta de Competencias integrada por dos miembros de la Suprema y otros dos del Consejo de Castilla. Resulta paradigmático al respecto un proceso que se inició en los años cuarenta del siglo XVII, cuando un tal Pedro Gómez de Travada fue encarcelado por los alcaldes de casa y corte tras ser acusado de bigamia.

La jurisdicción en las causas de bigamia, $y$ en general en todas las que atentaban contra la moral sexual, fue controvertida a lo largo de la Edad Moderna, dado que muchos juristas sostenían que estos abusos debían calificarse como asuntos de fuero mixto. De ahí que la justicia criminal defendiera que eran delitos de su competencia, mientras que la Inquisición los considerase pecados y reclamase su conocimiento ${ }^{20}$. Es lo que ocurrió tras el encarcelamiento de Gómez de Travada. Tal y como relató en una alegación el doctor Diego Escolano, inquisidor apostólico de Toledo ${ }^{21}$, la sala de alcaldes de casa y corte se atribuyó el conocimiento de la causa, arguyendo que era un delito de «mixto fuero», y se negó a entregar el preso a la Inquisición, a pesar de los repetidos requerimientos del Santo Oficio. Escolano dedicó buena parte de su alegación a demostrar que la bigamia era un delito eclesiástico y a defender, en consecuencia, la jurisdicción de los inquisidores en este proceso. El inquisidor apostólico de Toledo criticaba asimismo en su escrito, como no podía ser de otra manera, el comportamiento de los alcaldes de casa y corte y se lamentaba, porque no se había formado competencia y remitido «las informaciones sumarias a los superiores tribunales, para que se vean y determinen en la sala de competencias» ${ }^{22}$. Algo parecido aconteció

${ }^{20}$ Gacto Fernández, 1990; Villalba Pérez, 1993, p. 192; y Pablo Gafas, 2017, pp. 220-22I.

${ }^{21}$ «Por la jurisdicción del Santo Oficio de la Inquisición en las causas de fe con la sala de los señores alcaldes de casa y corte de su majestad. Sobre la inhibición en la causa de duplici matrimonio contra Pedro Gómez de Travada, preso en la cárcel de la villa, que pende en grado de apelación en dicha sala y que se debe remitir original al Santo Oficio, juntamente con el preso como se pide», BNE, Porcones, 954-44 (caja 2).

22 BNE, Porcones, 954-44 (caja 2), fol. 27v. 
unos años después en Canarias, tras estallar un conflicto entre la Real Audiencia y la Inquisición.

En I66I la Real Audiencia de Canarias apresó a un médico de la Inquisición ${ }^{23}$, Domingo Ramos de Feo. Según una alegación publicada por la Audiencia ${ }^{24}$, el tribunal del Santo Oficio se declaró juez competente en la causa e inhibió a la Audiencia, porque aseguraba que Domingo Ramos gozaba del fuero inquisitorial. Un fuero que la Audiencia no reconocía, ya que el galeno no ejercía exclusivamente como médico de la Inquisición, sino que desempeñaba un oficio «público y común a esta ciudad y a los vecinos de la isla» ${ }^{25}$. Ante esta situación, la Audiencia propuso que, como se acostumbraba en estos casos, se juntasen para dirimir el conflicto uno de los oidores del tribunal, Álvaro Gil de la Sierpe, y el inquisidor José Badarán de Osinalde. Sin embargo, el inquisidor «no se vino en ello» ${ }^{26}$ y la Audiencia declaró la competencia. De acuerdo con la concordia, el asunto debía quedar en suspenso hasta que la Junta de Competencias dictaminara, pero la Inquisición no tuvo en cuenta la declaración de la competencia y siguió con la instrucción de la causa, llegando a publicar un auto de excomunión contra el oidor Álvaro Gil de la Sierpe ${ }^{27}$.

Las alegaciones se hacían eco, por tanto, de las dificultades que entrañaba poner en marcha con el acuerdo de ambas partes el mecanismo de la competencia previsto en la concordia, lo que impedía que las Juntas de Competencias resolviesen los conflictos. Esto no quiere decir, por supuesto, que estas juntas nunca llegaran a constituirse. De hecho, sabemos que dirimieron muchos asuntos, aunque, según denunciaron los autores de las informaciones en derecho que tenemos en nuestras manos, no siempre cumplieron escrupulosamente con su cometido, esto es, remitir «el conocimiento de las causas llanamente, y sin otro conocimiento de causa, ni otro estrépito y figura de juicio a los Inquisidores o a los jueces seglares» ${ }^{28}$. Veamos algunos casos.

En la década de los cuarenta del Seiscientos tuvo lugar un proceso criminal entre Catalina de Yegros y un familiar del Santo Oficio, el alcalde de la villa de Azuaga Alonso de la Vera, al que esta acusaba de haber mandado asesinar a su

${ }^{23}$ Galván Rodríguez, 2016, p. 23.

${ }^{24}$ «Por la Audiencia de las Islas de Canarias, en los autos de la competencia, con el Tribunal de la Inquisición de ellas, sobre la prisión del doctor Domingo Ramos de Feo, médico», BNE, Porcones, 389-22.

25 BNE, Porcones, 389-22, fol. 2v.

${ }^{26}$ BNE, Porcones, 389-22, fol. IV.

27 BNE, Porcones, 389-22, fol. 9v-10r. No era la primera vez que la Inquisición excomulgaba a Gil de Sierpes. Ya lo había hecho en 1654, porque el oidor había procedido contra el alcaide de las cárceles secretas del tribunal, Lobo Cabrera y Regueira Benítez, 2000, pp. 105-106.

${ }^{28}$ Novisima Recopilación, II, 7, I. 
marido ${ }^{29}$. Alonso de la Vera quiso acogerse al fuero inquisitorial, pero Catalina de Yegros se opuso, porque consideraba que el asesinato de su marido constituía un delito de muerte alevosa - una las causas criminales exceptuadas en la concordia- y que, en consecuencia, el caso debía juzgarlo la justicia ordinaria. Una vez reconocida la competencia, el asunto se vio primero en una Junta de Competencias formada por miembros de la Suprema y del Consejo de Castilla y, finalmente, se remitió en discordia a la Junta Mayor de Competencias para que determinase $^{30}$. En este momento ambas partes hicieron circular sendas alegaciones ${ }^{31}$, donde además de defender su postura, le recordaban a los miembros de la junta que su función no era decidir sobre la culpabilidad o inocencia de Alonso de la Vera, sino resolver «el artículo de la competencia... para fundar la jurisdicción»» ${ }^{32}$. Así pues, estas informaciones en derecho dejaban entrever una crítica velada a la Junta Mayor de Competencias, porque, al parecer, a la hora de dictaminar tenía en cuenta algunos elementos de juicio que no le correspondía valorar. Con mayor rotundidad se expresa en unas alegaciones jurídicas redactadas en un caso de desafío acaecido en Granada.

En 1642 el consejero de Guerra Pedro Valle de la Cerda le encargó a un alcalde de hijosdalgo de la Chancillería de Granada, Francisco Guillén del Águila ${ }^{33}$, adquirir veinte caballos «para el servicio de su majestad» ${ }^{34}$. Un vecino de Granada, don Gómez de Montalvo, le proporcionó dos ejemplares al alcalde; sin embargo, este no se los entregó a Pedro Valle de la Cerda, sino a Diego Laso de Castilla, quien, siguiendo órdenes del conde de Oñate, también estaba comprando caballos en la ciudad del Darro ${ }^{35}$. Gómez Montalvo le envió entonces una

${ }^{29}$ Archivo Histórico Nacional [en adelante AHN], Inquisición, leg. 1981, exp. 3.

${ }^{30}$ BNE, Porcones, 954- 4 (caja 2), fol. I r-Iv. Como indiqué, cuando se declaraba una competencia y los ministros de la Junta no llegaban a un acuerdo, resolvía en última instancia la Junta General de Competencias. Así sucedió, por ejemplo, en una causa que se disputaban la Chancillería de Valladolid y el tribunal de Inquisición concerniente al comisario del Santo Oficio Pedro Pecha de Torres. El asunto se vio «en sala de competencia, y por no se haber conformado los dos Consejos, se hizo consulta a su majestad, la cual se ha remitido a la Junta Grande», BNE, Porcones, 954-22 (caja 2), fol. 259r.

31 «Por doña Catalina de Yegros, viuda de don Pedro Vázquez Caballero, con Alfonso de la Vera, alcalde ordinario de la villa de Azuaga, familiar del Santo Oficio de la Inquisición de Llerena», BNE, Porcones, 954-14 (caja 2); $y$ «Por Alonso de la Vera, familiar del Santo Oficio de la Inquisición, vecino y alcalde ordinario de la villa de Azuaga con doña Catalina de Yegros, viuda de don Pedro Vázquez, difunto, vecino que fue de la dicha villa sobre la competencia», Biblioteca de la Universidad de Sevilla [BUS], A 109/09 (3I).

32 BUS, A $109 / 09$ (3I), fol. I0v.

${ }^{33}$ Ejercía como alcalde de hijosdalgo de la institución desde 1638, AHN, Consejos, leg. 13515.

${ }^{34}$ BNE, Porcones, 954-33 (caja 2). Pedro Valle de la Cerda fue nombrado consejero de Guerra el 25 de marzo de 1642 , coincidiendo con su designación como proveedor general del Ejército de Cataluña, Gómez González, 2016, p. 248.

35 BNE, Porcones, 954-33 (caja 2). Estaban destinados a dos compañías de Montados que el Consejo de Órdenes iba a ofrecer a su majestad, Gómez González, 201 I, p. 35. 
misiva a Guillén del Águila retándole a un duelo y, aunque el desafío no tuvo lugar, fue apresado por los ministros de la Chancillería ${ }^{36}$. De inmediato, se formó competencia entre la Chancillería y la Inquisición de Granada, ya que Gómez de Montalvo alegó ser familiar del Santo Oficio.

Sobre este caso contamos con tres alegaciones jurídicas. En la primera, el fiscal de la Chancillería, Juan Pérez de Lara, afirmaba escribir la alegación

para que a los señores de los Consejos Supremos de Castilla y Inquisición (en la junta de estas competencias) conste de la clara justicia que el Real Acuerdo de los señores presidente y oidores desta Chancillería... tiene para conocer desta causa y castigar a don Gómez de Montalvo y Figueroa, en el delito grave que ha cometido del desafío que por el dicho papel escrito y firmado de su nombre hizo al señor don Francisco Guillén del Águila ${ }^{37}$.

El fiscal del tribunal granadino intentaba probar dos hechos: I) que Gómez Montalvo no podía gozar del fuero, porque era familiar de número de Toledo y no de Granada, donde vivía con su familia y tenía sus casas principales; y 2) que el delito de desafío era uno de los exceptuados en la concordia.

La segunda alegación que ha llegado a nuestras manos es obra del fiscal del Consejo de Castilla Juan Morales Barnuevo ${ }^{38}$. Morales Barnuevo también se dirigía en su escrito a la Junta de Competencias y, partiendo de la información en derecho de Pérez de Lara, defendía que el delito de desafío competía a la justicia ordinaria. Pero lo interesante de esta alegación no es la defensa de jurisdicción en sí misma, sino la reflexión del fiscal del Consejo de Castilla acerca de las resoluciones adoptadas por la junta cuando las disputas jurisdiccionales se referían a los delitos exceptuados en la concordia. Afirmaba que en ocasiones los miembros de la junta habían tenido en cuenta a la hora de dictaminar la culpabilidad o inocencia del familiar que había cometido el delito, en virtud de lo cual se habían remitido casos a la Inquisición «por descuido». A su juicio, la junta debía remediarlo y limitarse a establecer «si el delito es de los exceptuados o no, que esto

\footnotetext{
36 BNE, Porcones, 954-33 (caja 2).

37 «El licenciado don Juan Pérez de Lara, fiscal de su majestad en esta Real Audiencia y Chancillería por su real jurisdicción. En la competencia con el tribunal del Santo Oficio de la Inquisición. Sobre la causa del desafío que don Gómez de Montalvo y Figueroa, vecino desta ciudad, hizo por un papel al señor don Francisco Guillén del Águila, alcalde de hijosdalgo en esta corte», BNE, Porcones, 954-3I (caja 2), fol. 3v.

38 «Discurso legal del licenciado don Juan Morales y Barnuevo, caballero del hábito de Alcántara del Consejo de su majestad y fiscal dél. Por el Consejo y la justicia ordinaria de su majestad. En competencia con el Consejo de la Santa y General Inquisición y la jurisdicción real que ejerce. Sobre haber desafiado don Gómez de Montalvo y Figueroa, vecino de Granada, y familiar que pretende ser del Santo Oficio a don Francisco Guillén del Águila, alcalde de los hijosdalgo en la Real Chancillería de Granada, y caballero de la orden de Santiago», BNE, Porcones, 954-32 (caja 2).
} 
solo es lo que se debe disputar y determinar en la Junta ( $y$ hablando con el respeto que debo), para lo que tiene la Junta jurisdicción ${ }^{39}$.

En consecuencia, según el fiscal del Consejo de Castilla, la Junta de Competencias se había extralimitado en sus funciones y había favorecido los intereses del Santo Oficio. Una afirmación que no compartía el autor de la tercera alegación escrita sobre este asunto ${ }^{40}$. Se trata de una información en derecho mandada publicar por la Inquisición de Granada, en la que el autor interpelaba al fiscal del Consejo de Castilla y defendía tanto la jurisdicción del Santo Oficio como «la autoridad... de tan grandes ministros como han juzgado las competencias», pues sostenía que siempre habían actuado con igualdad, sin beneficiar a ningún tribunal ${ }^{4}$. No es de extrañar que en esta última alegación se aplaudiesen las decisiones adoptadas por los ministros que juzgaban las competencias, pues, como indiqué, hasta mediados del siglo XVII la mayoría de los conflictos jurisdiccionales se resolvieron a favor del Santo Oficio.

En definitiva, las alegaciones que manejamos muestran que en la práctica la forma «amistosa» de solventar los problemas de jurisdicción prevista en la concordia estuvo plagada de obstáculos. A las dificultades que entrañaba la declaración misma de la competencia hay que añadir la controversia que generaban las decisiones de la Junta Mayor de Competencias y de las Juntas de Competencias integradas por ministros de los Consejos de Castilla y de la Inquisición, cuando sus miembros entraban a valorar cuestiones que no le correspondían. Al hacerse eco de esta realidad, las informaciones en derecho agravaban aún más las desavenencias entre los tribunales reales y el Santo Oficio, ya que la Inquisición consideraba que estos escritos menoscababan su autoridad. De ahí que la Suprema llegase a censurarlos, lo que dio lugar a la creación de nuevas juntas.

\section{LA CENSURA INQUISITORIAL A LAS ALEGACIONES JURÍDICAS EN DEFENSA DE LA JURISDICCIÓN REAL}

La historiografía ha puesto de manifiesto que tanto en Castilla como en Aragón la Inquisición censuró obras de carácter jurídico, especialmente si ponían en entredicho su jurisdicción ${ }^{42}$. Algunos de los escritos jurídicos censuradas por

\footnotetext{
${ }^{39}$ BNE, Porcones, 954-32 (caja 2), fol. 4v.

40 «Por la jurisdicción de la Inquisición de la ciudad y reino de Granada, en el caso de competencia sobre el desacato que se imputa haber cometido don Gómez de Montalvo, familiar del Santo Oficio», BNE, Porcones, 954-30 (caja 2).

41 En la Junta General de Competencias, escribe, «no hay riesgo de inclinarse a favorecer más la una parte que la otra, ni de que querrán que el delito no quede castigado, sino que con toda igualdad como siempre se ha hecho, dará a cada tribunal lo que es suyo», BNE, Porcones, 954-30 (caja 2), fol. I7v.

42 Alvarado, 2000; y Planás Roselló, 2014.
} 
el Santo Oficio fueron precisamente informaciones en derecho publicadas durante el estallido de un conflicto de competencias ${ }^{43}$. En ocasiones, el Consejo de Castilla se opuso con vehemencia a la reprobación de estas obras y planteó que la decisión de censurarlas quedase en manos de una junta. Tal cosa sucedió tras la censura inquisitorial de dos alegaciones jurídicas publicadas en Granada y Sevilla en el primer tercio del siglo XVII.

En abril de 1623 tuvo lugar un encuentro entre la Chancillería de Granada y el tribunal de la Inquisición que provocó un gran escándalo en la ciudad. El conflicto surgió cuando los alcaldes del crimen condenaron a galeras a «un hombre de baja suerte», Jerónimo Palomino, por blasfemar y acuchillar una cruz ${ }^{44}$. La Inquisición reclamó el conocimiento de la causa, al considerar que se trataba de delitos contra la fe, y liberó al preso. Sin embargo, la Chancillería no reconoció la jurisdicción inquisitorial y encarceló a algunos oficiales del Santo Oficio. La respuesta de la Inquisición no se hizo esperar: procedió con censuras y excomulgó a los alcaldes del crimen. El caso tuvo tal trascendencia que el Inquisidor general, Andrés Pacheco, avocó la causa ${ }^{45}$, de manera que la competencia no se dirimió en una junta como estaba establecido, sino que Felipe IV, en palabras de Lea, «tomó el asunto en sus propias manos» y resolvió a favor de la Inquisición, a pesar de que el Consejo de Castilla manifestase en un memorial dirigido a Olivares «que la situación a que se había visto reducida la Chancillería de Granada era la más ignominiosa de que se hubiera oído jamás en España, en especial, considerando cuán leve era la causa de toda esa agitación ${ }^{46}$. Ahora bien, la resolución del monarca no puso punto final al conflicto.

En el mes de junio de 1623, llegó a oídos de los inquisidores de Granada que un oidor de la Chancillería estaba escribiendo una alegación en romance «impugnando el proceder deste Santo Oficio en el caso de la competencia» ${ }^{47}$. Los inquisidores intentaron impedir su publicación, «para que no triunfen los enemigos de la Inquisición de ver escritos que se opongan a la reverencia que se le debe ${ }^{48}$, a pesar de lo cual, la información vio la luz, aunque sin nombre de autor ni de impresor, estampándose en la primera hoja

\footnotetext{
43 No fueron estas las únicas alegaciones jurídicas que censuró la Inquisición. En este momento me encuentro realizando una investigación de mayor calado sobre la censura inquisitorial de informaciones en derecho, en la que me propongo profundizar sobre la cuestión.

${ }^{44}$ Henríquez de Jorquera, 1987, p. 653.

45 BNE, Porcones, I388-28.

${ }^{46}$ Lea, 1983, I, p. 542.

${ }^{47}$ AHN, Inquisición, leg. 2617.

${ }^{48} \mathrm{AHN}$, Inquisición, leg. 2617.
} 


\section{INÉS GÓMEZ GONZÁLEZ}

las armas reales de Castilla y León, autorizando con su protección lo que tanto a Su Majestad ofende como es que semejantes escriptos se escriban contra la Inquisición, contra la fe y contra los buenos usos de ella» ${ }^{49}$.

La Inquisición granadina, siguiendo órdenes del Inquisidor General y del Consejo de la Inquisición, inició una pesquisa y averiguó que el autor de la alegación era efectivamente un oidor de la Chancillería, Luis Gudiel de Peralta ${ }^{50}$, y que se habían impreso cincuenta y un ejemplares en la imprenta de Francisco Heylan, a cuya financiación había contribuido la Chancillería con 600 reales. Se descubrió asimismo que Gudiel había hecho circular su escrito en Granada y Madrid, donde envió veinte copias que distribuyó entre consejeros, amigos y colegiales del Colegio del Arzobispo ${ }^{51}$ en el que había estudiado ${ }^{52}$. El 19 de septiembre los inquisidores remitieron los autos al Consejo junto a un ejemplar de la alegación y solicitaron que se mandase recoger, «porque la publicidad de este atrevimiento obliga a algún cuidado y a impedir que el daño nos pase más adelante ${ }^{53}$. La resolución de los calificadores fue categórica: el 26 de septiembre «convinieron todos unánimes y conformes en que la dicha información se debía recoger y prohibir» por contener doctrina «escandalosa» $y$ «digna de censura» ${ }^{54}$. Unos días después, el 5 de octubre, se publicó el edicto de censura en la catedral y otras iglesias de Granada, lo que causó «miedo y reverencia» en la ciudad. La Inquisición logró recoger veintiún ejemplares y el propio Gudiel, «muy arrepentido», entregó a la Inquisición todas las copias que tenía en su poder ${ }^{55}$. Pero ¿qué proposiciones contenía esta información en derecho que tanto ofendían a los inquisidores?

En la alegación, que afortunadamente hemos podido localizar ${ }^{56}$, Gudiel narraba con todo lujo de detalles los acontecimientos que habían provocado el desencuentro y defendía con firmeza la actuación de la Chancillería y la jurisdicción real, que, en su opinión, había sido perturbada por la Inquisición. El oidor sostenía que la causa no competía al Santo Oficio, porque las blasfemias cometidas por Palomino no eran hereticales. Afirmaba igualmente que la Inquisición se

\footnotetext{
${ }^{49}$ AHN, Inquisición, leg. 2617.

${ }^{50}$ AHN, Inquisición, leg. 2617. Fue oidor de la institución desde el 20 de abril de 1617 al 18 de agosto de 1624 , AHN, Consejos, leg. 13517.

${ }^{51}$ AHN, Inquisición, leg. 2617.

52 Había sido colegial del colegio del arzobispado de Salamanca, Ferrer Ezquerra y Misol García, 1956, p. 56.

${ }^{53}$ AHN, Inquisición, leg. 2617.

${ }^{54}$ AHN, Inquisición, leg. 2617. Sobre los calificadores, López Vela, 1992.

${ }^{55} \mathrm{AHN}$, Inquisición, leg. 2617.

56 «Por la jurisdición real, y alcaldes del crimen de la Audiencia y Chancillería de Granada. En los casos de competencias de jurisdicción, con el Tribunal de la Inquisición de la misma ciudad», BNE, Porcones, I388-28.
} 
extralimitó al proceder por censuras, ya que se trataba de un conflicto de competencias, por lo que, de acuerdo con la concordia de 1553, el caso debía conocerlo la Junta de Competencias, «en que se juntan con dos señores del Consejo de Justicia otros dos de la General Inquisición ${ }^{57}$. Y negaba asimismo que el Inquisidor General pudiese avocar la causa. Por esta razón, concluía que el único remedio «para sosegar esta tempestad y todas las que se levantaren adelante, y conservar entre estos tribunales paz» era «guardar la concordia y cédulas Reales de Su Majestad, mandando que como se suele juntar, se junte hoy la Sala de competencias, para declarar quien ha excedido y cuya es la jurisdicción ${ }^{58}$.

Indudablemente, la alegación cuestionaba tanto la jurisdicción de la Inquisición como el procedimiento seguido en la resolución del conflicto, puesto que no se había formado una Junta de Competencias. Su contenido era similar al de otras informaciones en derecho; sin embargo, la publicación y posterior censura de esta alegación planteó un debate muy interesante entre el Santo Oficio y el Consejo de Castilla sobre la circulación de este tipo de escritos. El propio Inquisidor General Andrés Pacheco escribió al monarca sobre el asunto en septiembre de 1623:

[...] Es muy grande inconveniente consentir como de ordinario se consiente imprimir memoriales, y dándoles algunos nombres de informaciones sin nombres de autores, porque con esto se atreven a publicar papeles muy perjudiciales y de mala doctrina, y que obligan a mandar recogerlos y pasan tan adelante que al mismo Santo Oficio se atreven a ofender, como ahora ha sucedido en un memorial que ... se imprimió en Granada, el cual no solo ha sido forzoso recoger, sino también hacer diligencia para saber el autor y castigarle ejemplarmente ${ }^{59}$.

El Inquisidor General era partidario, por tanto, de censurar las alegaciones, postura que no compartía el Consejo de Castilla. El 7 de octubre de 1623 los consejeros elevaron una consulta al monarca en la que: I) defendían a Gudiel de Peralta y a otro ministro de la Chancillería, el fiscal Matías González de Sepúlveda, quien al parecer también había redactado una alegación a favor de la jurisdicción real; 2) solicitaban que el Inquisidor General suspendiese sus procedimientos; y 3) proponían «que se formase una junta donde se viesen los papeles en derecho y si hubiese en ellos algún exceso se enmendare $»^{60}$. El Consejo confiaba, en definitiva, en la convocatoria de una nueva junta, que examinara el contenido de la

${ }^{57}$ BNE, Porcones, 1388-28, fol. 17-18.

58 BNE, Porcones, I388-28, fol. 48v.

${ }^{59}$ Sierra y Corella, 1947, p. III.

${ }^{60}$ Consulta del Consejo a su majestad Carlos III, a súplica del Consejo de Inquisición, sobre las reglas dadas por su majestad para la expurgación y prohibición de libros, BNE, Mss. 10863, fol. 7/v-72v. No he logrado encontrar la alegación redactada por Matías González de Sepúlveda, aunque también se menciona su existencia en 
alegación y decidiera acerca de su censura. Esta junta debió convocarse, aunque no tengo ningún documento que lo acredite, dado que la alegación de Gudiel de Peralta aparece en el Índice de $1632^{61}$. Sí me consta su convocatoria unos años después, cuando la Suprema volvió a reprobar otra alegación.

En abril de 1637, los oidores de la Audiencia de Sevilla acusaron de desacato a un familiar del Santo Oficio, Alonso Tello, porque una mañana, yendo a caballo, pasó delante de unos oidores del tribunal y en lugar de apearse les saludó con la mano. Los oidores le condenaron a 200 ducados, interviniendo entonces la Inquisición, que procedió con censuras y reclamó la causa ${ }^{62}$. A los pocos días, el 9 de mayo de 1637, un fiscal de la Audiencia, Juan Pérez de Lara, dio a la luz una información en derecho ${ }^{63}$. En la misma relataba la conmoción que provocó el incidente en la ciudad - pues la Inquisición excomulgó a varios ministros de la Audiencia y publicó un edicto «como si fuera causa de fe» en la catedral con "grande escándalo y nota»-, a la vez que defendía la necesidad de formar competencia, porque el delito de desacato calificado era uno de los exceptuados en la concordia de $1553^{64}$. Solicitaba por ello que la Junta de Competencias resolviera la diferencia y que «castigara condignamente los escándalos y conmociones del pueblo que los Inquisidores han hecho, ocasionando los varios pareceres del vulgo desenfrenado» ${ }^{65}$.

Tal y como pedía el fiscal, el asunto lo vio una Junta de Competencias, que dictaminó a favor de la Audiencia ${ }^{66}$. Sin embargo, esta resolución no zanjó el conflicto, ya que el Santo Oficio, «al tiempo de cumplir la resolución», censuró la alegación escrita por Pérez de Lara y mandó recogerla en los primeros días de agosto, fijando edictos en la catedral, en las iglesias de la ciudad y en otros espacios públicos «para hacer más ruidosa la injuria del fiscal» ${ }^{67}$. El Consejo de Castilla, como había hecho en el caso de Gudiel de Peralta, elevó una representación al monarca, en la que defendía a los fiscales y ministros

que con tanto cuidado y desvelo entienden en su servicio y en defensa de la jurisdicción real..., pues de personas que con tanto acuerdo han sido elegidas para

AHN, Inquisición, leg. 2617.

61 Alvarado, 2000, p. 339.

62 Guichot, 1889, p. 239.

63 «Por la jurisdicción real, y el fiscal de su majestad, en esta Real Audiencia de Sevilla en la causa y procedido en ella; sobre el desacato calificado de don Alonso Tello, caballero del orden de Calatrava, y familiar del Santo Oficio», BNE, Porcones, 23-7.

64 BNE, Porcones, 23-7, fol. 226r-228v.

65 BNE, Porcones, 23-7, fol. 238v.

${ }^{66}$ BNE, Mss. 10863, fol. 65v.

${ }^{67}$ BNE, Mss. 10863, fol. 66r-66v. 


\section{LOS CONFLICTOS JURISDICCIONALES ENTRE LA JUSTICIA REAL Y EL SANTO OFICIO}

estos ministerios, se ha de presumir y fiar que lo que obran por escrito o de palabra está bien fundado y dentro de los límites jurídicos ${ }^{68}$.

En su escrito, los consejeros criticaban asimismo a la Inquisición, porque había ordenado que se recogiese el papel con «descrédito público» ${ }^{69}$. Sostenían igualmente que la alegación no contenía ninguna afirmación que justificase su censura. Y, finalmente, proponían que cuando el Santo Oficio se plantease censurar algún papel en defensa de la jurisdicción real no lo revisase el Consejo de la Inquisición, sino una junta integrada, bien por magistrados de los tribunales en conflicto, bien por «ministros libres de la sospecha de ser propia la causa y de competencia de tribunal dependiente suyo» ${ }^{70}$. Así lo ordenó el monarca, quien tras esta consulta mandó que se volviera a examinar la alegación de Pérez de Lara «por teólogos y letrados imparciales y no sospechosos al fiscal» ${ }^{71}$.

En esta ocasión, como he señalado, sí me consta la convocatoria de esta junta. No en vano, he localizado tres alegaciones jurídicas dirigidas a la misma ${ }^{72}$, que sus autores enviaron al fiscal del Consejo de Castilla Cristóbal Moscoso y Córdoba, para que las hiciese llegar al resto de consejeros y a los «señores de la Junta que su Majestad ha nombrado para este casoı ${ }^{73}$. Estas informaciones en derecho justificaban por un lado, como ya habían hecho los consejeros de CastiIla, la labor de los fiscales en general, y de Pérez de Lara en particular, en pro de la jurisdicción real; y, por otro, dudaban de la capacidad del Santo Oficio para recoger los papeles en derecho, «cuando no hay proposición que reciba calificación de fe... por solo escándalo (que dice causa) ${ }^{74}$. Obviamente, también refutaban las calificaciones hechas por la Suprema al escrito de Pérez de Lara ${ }^{75}$ y

68 BNE, Mss. 10863, fol. 67r-67v. La consulta es de 20 de agosto de 1637, fol. 87v.

${ }^{69}$ BNE, Mss. 10863, fol. 67v.

70 BNE, Mss. 10863, fol. 68r.

71 BNE, Mss. 10863, fol. 69v.

72 «En defensa del papel que ha hecho el fiscal de su majestad de la Audiencia de Sevilla, en la competencia de la causa de don Alonso Tello (que se mandó recoger) para informar a los señores de la Junta», BNE, Varios Extravagantes, 217-4I; «En defensa del papel que hizo el licenciado don Juan Pérez de Lara, fiscal de su majestad de la Real Audiencia de Sevilla. En la competencia de la causa de don Alonso Tello, que se recogió. Para informar a los señores de la Junta que su majestad mandó hacer: y a los calificadores teólogos, y juristas de aprobación grande, que ha mandado nombrar», BNE, Porcones, I62-18 (I); y «Defensa del fiscal de su majestad, de la Audiencia de Sevilla, sobre el papel mandado recoger», BNE, Porcones, 954-48 (caja 2).

73 BNE, Porcones, 954-48 (caja 2), fol. 3r.

74 BNE, Porcones, 162-18 (I), fol. 2v.

75 Las tres calificaciones hechas por el Santo Oficio fueron las siguientes: la primera sobre «que la jurisdicción de los Inquisidores en los delitos de los familiares era temporal, y que, en los casos de competencia con los jueces seglares, no podían, ni debían proceder por censuras... La segunda, de haber dicho que su majestad en lo temporal es vicario de Cristo Nuestro Señor... La tercera, de haber dicho... que su majestad recibe la jurisdicción temporal immediate a Crhisto Domino... que el pontífice era vicario de Cristo en lo espiritual y como tal se le reconoce por cabeza, pero que lo era el rey, nuestro señor, en lo temporal», BNE, Porcones, 
negaban igualmente que este atacara de algún modo a la Inquisición o a los privilegios y exenciones de sus ministros y oficiales. Ahora bien, estas alegaciones no convencieron a los miembros de la junta, pues la información en derecho de Pérez de Lara fue prohibida in totum ${ }^{76}$.

\section{CONCLUSIONES}

Como indiqué al inicio de estas páginas, los conflictos de competencias entre los tribunales reales y el Santo Oficio fueron una constante a lo largo del Antiguo Régimen, a pesar de que en Castilla la concordia de 1553 delimitó el ámbito de actuación de ambas jurisdicciones. Estos conflictos tuvieron gran repercusión en la sociedad y dieron lugar a la circulación de un sinfín de alegaciones jurídicas. Los autores de estas informaciones en derecho, a la vez que defendían los intereses de los tribunales que habían propiciado su publicación, evidenciaban los problemas que planteaba poner en marcha el mecanismo previsto en la concordia para solucionar las controversias jurisdiccionales. De hecho, denunciaban que a veces fue imposible declarar la llamada competencia y que, en consecuencia, no se pudo convocar la Junta de Competencias integrada por dos miembros del Consejo de Castilla y otros dos de la Suprema. Es más, mostraban que cuando se declaraba la competencia sin el acuerdo de ambas partes, la convocatoria de la Junta de Competencias perdía buena parte de su razón de ser, ya que no se detenía la instrucción de las causas a la espera de la resolución de la junta como era preceptivo.

Por otra parte, las alegaciones jurídicas ponían en entredicho el funcionamiento tanto de las Juntas de Competencias formadas por consejeros de Castilla y de la Inquisición como de la Junta Mayor de Competencias. No en vano, en muchos casos sus miembros no se limitaron a dilucidar a qué tribunal le correspondía resolver el proceso sobre el que se había formado la competencia, sino que dictaminaron teniendo en cuenta elementos de juicio que escapaban a su jurisdicción.

Las informaciones en derecho reflejaban, por tanto, la dificultad que entrañaba resolver los conflictos jurisdiccionales a través de juntas. Pero, además, como he señalado, la circulación de estos escritos planteó otro problema añadido: el de su censura. Efectivamente, la censura de algunas alegaciones jurídicas por parte de la Inquisición encontró la oposición del Consejo de Castilla, lo que dilató en el tiempo la resolución de estos conflictos, que no concluyeron hasta

162-18 (I), fol. Ir.

${ }^{76}$ Alvarado, 2000, p. 339. 


\section{LOS CONFLICTOS JURISDICCIONALES ENTRE LA JUSTICIA REAL Y EL SANTO OFICIO}

que se convocaron nuevas juntas de teólogos y letrados, cuya misión era pronunciarse acerca de la reprobación de las alegaciones censuradas.

\section{BibLIOGRAFÍA}

Alvarado, Javier, «Juristas turbadores: la censura inquisitorial a la literatura jurídica y política (siglos XVI-XVII)», en Historia de la literatura jurídica en la España del Antiguo Régimen. l, ed. Javier Alvarado Planas, Madrid, Marcial Pons, 2000, pp. 33I-385.

Baltar Rodríguez, Juan Francisco, Las juntas de gobierno en la monarquía hispánica (siglos XVI-XVII), Madrid, Centro de Estudios Políticos y Constitucionales, 1998.

Barrios, Feliciano, La gobernación de la monarquía de España: Consejos, Juntas y Secretarios de la administración de Corte (I556-1700), Madrid, Centro de Estudios Políticos y Constitucionales, 2015.

Contreras, Jaime, El Santo Oficio de la Inquisición de Galicia (poder, sociedad y cultura), Madrid, Akal, 1982.

Coronas González, Santos María, «Alegaciones e informaciones en derecho (porcones) en la Castilla del Antiguo Régimen», Anuario de Historia del Derecho español, 73, 2003, pp. I65-192.

Domínguez Ortiz, Antonio, «La monarquía, los poderes civiles y la inquisición, un arbitraje difícil», en Estudios de la Inquisición española, ed. Antonio Domínguez Ortiz y Ricardo García Cárcel, Granada, Comares, 2010, pp. 75-88.

Domínguez Ortiz, Antonio, «Las presuntas “razones” de la Inquisición», en Historia de la Inquisición en España y América. III, dir. Bartolomé Escandell Bonet y Joaquín Pérez Villanueva, Madrid, Biblioteca de Autores Cristianos, 2000, pp. 57-82.

Egido, Teófanes, «La Inquisición de una España en guerra», en Historia de la Inquisición en España y América. I, dir Bartolomé Escandell Bonet y Joaquín Pérez Villanueva, Madrid, Biblioteca de Autores Cristianos, 1994 PP. I 227-I 304.

Ezquerra Revilla, Ignacio, «El Consejo Real durante el reinado de Felipe IV», en La corte de Felipe IV (I 62 I- I 665). Reconfiguración de la monarquía católica. El sistema de corte. Consejos y Hacienda, dir. José Martínez Millán y Manuel Rivero Rodríguez, Madrid, Ediciones Polifemo, 2017, III, 2, pp. 77I- 855.

Ferrer Ezquerra, Luis e Higinio Misol García, Catálogo de colegiales del Colegio Mayor del Arzobispado de Salamanca, Salamanca, Universidad de Salamanca, 1956.

Gacto Fernández, Enrique, «El delito de bigamia y la inquisición española», en Sexo barroco y otras transgresiones premodernas, ed. Francisco Tomás y Valiente, Madrid, Alianza Universidad, 1990, pp. I27-I52.

Gacto Fernández, Enrique, «Apuntes sobre la jurisdicción del Santo Oficio», en Estudios jurídicos sobre la Inquisición española, ed. Enrique Gacto Fernández, Madrid, Dykinson, 2012, pp. 13-18.

Galván Rodríguez, Eduardo, «Una perspectiva del tribunal de la Inquisición de Canarias», Revista de la Inquisición. Intolerancia y derechos humanos, 20, 2016, pp. II-36.

García-Badell Arias, Luis María, «La Junta Grande de competencias de Felipe IV: rey, nobleza y Consejos en la monarquía católica», Cuadernos de Historia del Derecho, Extraordinario, 2004, pp. 105-136.

Guichot, Joaquín, Historia de la ciudad de Sevilla. Segunda Parte. Siglo XVII, Sevilla, Establecimiento tipográfico de «El Progreso», 1889.

Gómez González, Inés, «Más allá de la colegialidad. Una aproximación al juez de comisión en la España del Antiguo Régimen», Chronica Nova, 37, 201 I, pp. 21-40.

Gómez González, Inés, «Entre la corrupción y la venalidad: don Pedro Valle de la Cerda y la visita al Consejo de Hacienda de 1643», en Mérito, venalidad y corrupción en España y América, siglos XVII y XVIII, dir. Francisco Andújar Castillo y Pilar Ponce Leyva, Valencia, Albatros, 2016a, pp. 235-249.

Gómez González, Inés, «“En defensa de los ministros afligidos de Su Majestad”. Las alegaciones jurídicas (porcones) en favor de los jueces del Antiguo Régimen», en Justicias, agentes y jurisdicciones. De la monarquía hispánica a los Estados Nacionales (España y América, Siglos XVI-XIX), coord. Elisa Caselli, Madrid, Fondo de Cultura Económica, 2016b, pp. 197-218.

Gómez González, Inés, «Sobre el matrimonio de los magistrados de las Audiencias indianas: prohibición real y defensa judicial de los ministros inculpados en el siglo XVII», L'Atelier du Centre de Recherches Historiques, 20, 2019, pp. I-28.

Henríquez de Jorquera, Francisco, Anales de Granada. Descripción del Reino y ciudad de Granada. Crónica de la Reconquista (1482-1492). Sucesos de los años 1588 a I646, Granada, Universidad de Granada, 1987.

Lea, Henry Charles, Historia de la Inquisición española, Madrid, Fundación Universitaria española, $1982-1983$. 


\section{INÉS GÓMEZ GONZÁLEZ}

Lobo Cabrera, Manuel y Luis Regueira Benítez, «El oidor de la Audiencia de Canarias don Álvaro Gil de la Sierpe y su librería», Anuario de Estudios Atlánticos, 46, 2000, pp. 97-I 44.

López Vela, Roberto, «El calificador en el procedimiento y la organización del Santo Oficio. Inquisición y órdenes religiosas en el siglo XVI», en Perfiles jurídicos de la Inquisición española, ed. José Antonio Escudero, Madrid, Instituto de Historia de la Inquisición-Universidad Complutense, 1992, pp. 345-390.

López Vela, Roberto, «Estructuras administrativas del Santo Oficio», en Historia de la Inquisición en España y América, dir. Bartolomé Escandell Bonet y Joaquín Pérez Villanueva, Madrid, Biblioteca de Autores Cristianos, 1993, II, pp. 63-274.

López Vela, Roberto, «Inquisición y cambio dinástico: la defensa de la constitución católica de la monarquía (1696-1715)», en Europa en torno a Utrecht, ed. Marina Torres Arce y Susana Truchuelo García, Santander, Editorial Universidad de Cantabria, 2014, pp. 3| I-35।.

Llorente, Juan Antonio, Consultas del Real y Supremo Consejo de Castilla y otros papeles sobre atentados contra la soberanía del Rey y su Real jurisdicción. Obra muy útil a los abogados y jueces como también a los aficionados a la historia de España. La da a luz don Astreófilo Hispano, París, Imprenta de A. Bobée, I8I8.

Llorente, Juan Antonio, Historia crítica de la Inquisición de España, Barcelona, Imprenta de Oliva, I835-1836.

Maqueda Abreu, Consuelo, «Conflictos jurisdiccionales y competencias en la Castilla del siglo XVII. Un caso ilustrativo», Anuario de Historia del Derecho Español, 67, 1997, pp. I569-I 588.

Martínez Millán, José, «Los problemas de jurisdicción del Santo Oficio: “La Junta Magna” (1696)», Hispania Sacra, 37, 1985, pp. 205-259.

Martínez Millán, José, «Los problemas de la Inquisición en tiempos de Carlos Il», Librosdelacorte.es, Monográfico 6, 2017a, pp. II-38.

Martínez Millán, José, «Luchas faccionales y reformas administrativas», en La corte de Felipe IV (I62 I-I665). Reconfiguración de la monarquía católica. Educación del rey y organización política, dir. José Martínez Millán y Manuel Rivero Rodríguez, Madrid, Ediciones Polifemo, 20I7b, III, I, Pp. 319-35I.

Melo Flórez, Jairo, «Pleitos de competencias del Santo Oficio con la justicia real durante los reinados de Felipe IV y Carlos II», Historia, Crimen y Justicia, 06/05/2016.

Novísima Recopilación de las leyes de España, Madrid, s. n., 1805.

Pablo Gafas, José Luis de, La sala de alcaldes de casa y corte (I583-1834). Justicia, gobierno y policía en la corte de Madrid, Madrid, ACCl ediciones, 2017.

Planas Roselló, Antonio, «Las alegaciones jurídicas y otros papeles en derecho (Mallorca, XVI-XIX)», lus Fugit, 17, 2014, pp. 105-126.

Recopilación de las leyes destos reinos hecha por mandado de la majestad católica del rey don Felipe Segundo, Madrid, Catalina de Barrio y Angulo, 1640.

Sánchez González, Dolores María, El deber de consejo en el Estado Moderno. Las Juntas “ad hoc” en España (147/-1665), Madrid, Ediciones Polifemo, 1993.

Sánchez González, Dolores María, Las Juntas Ordinarias. Tribunales permanentes en la corte de los Austrias, Madrid, UNED, 1995.

Sierra y Corella, Antonio, La censura de libros en España y los índices de catálogos españoles de los prohibidos y expurgados, Madrid, Cuerpo Facultativo de Archiveros, Bibliotecarios y Arqueólogos, 1947.

Tomás y Valiente, Francisco, «Relaciones de la Inquisición con el aparato institucional del Estado», en Gobierno e instituciones en la España del Antiguo Régimen, Madrid, Alianza Universidad, 1982, pp. 13-35.

Vallejo García-Hevía, José María, «Macanaz y su propuesta de reforma del Santo Oficio», Revista de la Inquisición, 5, 1996, pp. |87-29|.

Villalba Pérez, Enrique, La administración de la justicia penal en Castilla y en la corte a comienzos del siglo XVII, Madrid, Actas, 1993. 